\title{
A inovação linguística: subjetificação e luta por reconhecimento
}

\author{
The Linguistic Innovation: subjectification and struggle \\ for recognition
}

\section{Lorenzo Vitral Universidade Federal de Minas Gerais - UFMG}

\section{Resumo}

Este artigo desenvolve uma discussão sobre a relação entre o fenômeno da inovação linguística e a noção de subjetificação ('subjectification') (cf. LANGACKER, 1990; 2006; TRAUGOTT, 1995; TRAUGOTT; DASHER, 2005; OCHS; SCHIEFFELIN, 1989). Propomos, de acordo com a literatura, que a inovação linguística é consequência de aspectos mentais ligados à subjetividade dos falantes e, em última instância, ao mecanismo psicossocial denominado de luta por reconhecimento, estabelecido na filosofia moderna, sobretudo por Hegel (1893 [1992]), e desenvolvido, na atualidade, por Honneth (2003). Ilustramos nossa reflexão com uma análise do fenômeno conhecido por gerundismo, que, de acordo com nossa visão, a partir de conteúdo modal, desenvolve valor de futuro próximo, o que atesta o papel da subjetificação no fenômeno da inovação linguística.

\section{Palavras-chave}

Inovação Linguística, Gramaticalização, Subjetificação, Luta por Reconhecimento, Gerundismo. 


\section{Abstract}

This paper presents a discussion of the relationship between the phenomenon of linguistic innovation and the notion of subjectification (cf. LANGACKER, 1990; 2006; TRAUGOTT, 1995; TRAUGOTT; DASHER, 2005; OCHS; SCHIEFFELIN, 1989). We propose, according to the literature, that the linguistic innovation is a consequence of mental aspects linked with the subjectivity of speakers and, in the last instance, with a psychosocial mechanism named struggle of recognition, proposed in modern philosophy by Hegel (1893 [1992]), and developed nowdays by Honneth (2004). We exemplify our reflection with an analysis of the phenomenon known as gerundism, which, according to our view, beginning with modal content, develops proximate future value, confirming the role of subjectification in the phenomenon of linguistic innovation.

\section{Keywords}

Linguistic Innovation, Grammaticalization, Subjectification, Struggle for Recognition, Gerundism. 


\section{Introdução}

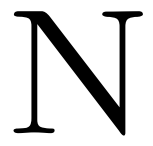

as descrições da gênese das perífrases verbais em qualquer língua, é procedimento usual considerar que um verbo de natureza lexical, isto é, de conteúdo substantivo, se inova no que concerne ao significado - e, dependendo do estágio em que se observa o processo, também no que diz respeito à sua forma -, passando a ser empregado como um verbo auxiliar o qual, ao se fazer seguir por uma das chamadas formas nominais do verbo, gera, por fim, as locuções ou perífrases verbais.

A formação dessas perífrases depende, assim, de um processo de gramaticalização que é responsável por converter um verbo lexical num verbo auxiliar. Processos desse tipo parecem ser constantes nas línguas e, como comentam Hopper e Traugott (1993), há uma tendência de as formas analíticas substituírem as formas sintéticas quando se observam estágios destacados de uma língua ou mesmo a relação de parentesco entre línguas. É o caso, por exemplo, da formação do futuro em francês, a partir de formas fonte do indo-europeu e do latim, como o mostra o seguinte quadro proposto em Hopper e Traugott (Op. cit., p. 10):
(1) Pré-latim
Latim
francês
*?
$>$ cantabimus
cantare habemos > chanterons
allons chanter $>$ ?

Como se vê, a forma perifrástica pré-latina deu origem a uma forma sintética no latim clássico que, em seguida, gerou uma forma perifrástica com o auxiliar habere, a qual, por sua vez, permitiu o surgimento, no francês, da forma sintética chanterons que, paralelamente, passou a contar com uma forma perifrástica implementada a partir da gramaticalização do verbo aller. A forma 
perifrástica termina por competir com a forma sintética, podendo ou não causar o desaparecimento da forma sintética com o mesmo valor de verdade. Essa descrição serve também para o português que dispõe, como é sabido, de uma forma sintética de futuro, como em cantaremos, cada vez menos usada, sobretudo na fala, que foi formada pela afixação do auxiliar haver; e de uma forma analítica, resultado da gramaticalização do verbo ir, como em vamos cantar.

Está de acordo com a descrição do fenômeno sistematizada por Hopper e Traugott (Op. cit.) a conhecida análise de Fleischman (1982) acerca da evolução da expressão do tempo futuro nas línguas românicas, que atesta a existência de processos cíclicos e contínuos envolvendo a alternância de formas sintéticas e analíticas. Fleischman destaca ainda um fenômeno por ela chamado de relevância do presente, a saber, as formas verbais que geram as formas perifrásticas de futuro são morfologicamente de tempo presente, ou seja, o futuro passa a ser expresso por um auxiliar no presente e uma forma nominal do verbo. $\mathrm{O}$ já citado caso da forma perifrástica portuguesa composta do auxiliar ir, no tempo presente, e do verbo principal no infinitivo serve como ilustração para o fenômeno destacado por Fleischman.

É decisivo considerar, igualmente, que o processo de alternância de formas sintéticas e analíticas e o fenômeno da relevância do presente, descritos por Fleischman, não são relevantes apenas para a formação do futuro. Observam-se essa alternância e também a relevância do presente na geração das formas que exprimem o passado. Kurylowicz (1965), um dos pioneiros da noção de gramaticalização, já apontava esse fenômeno nos processos de formação de perífrases verbais de passado na língua inglesa e em outras línguas.

Esse autor analisa a formação do tempo composto present perfect que, como é sabido, utiliza o auxiliar have, o qual, assim como no caso da formação do futuro, é empregado no presente. É também amplamente conhecido que, em várias línguas do domínio indo-europeu, entre elas, o português, o verbo equivalente a ter, que designa posse, é a fonte de um processo de gramaticalização que deu origem ao auxiliar ter.

Com base no que comentamos, importa destacar, por enquanto, que a criação de novas formas para exprimir o futuro e o passado é alimentada correntemente por auxiliares, resultantes de processos de gramaticalização, os quais estão, morfologicamente, no presente, ou seja, o fenômeno da relevância do presente, como nomeado por Fleischman, é relevante não apenas para a 
formação das perífrases de futuro, como também para a formação das que exprimem o passado.

Estamos agora em condiçôes de colocar as perguntas seguintes:

(2) a. a que se deve o fenômeno da relevância do presente?; e

b. que consequências teóricas esse fenômeno coloca em relação à perspectiva da gramaticalização?

Para tentar responder às perguntas acima, parto da ideia de que a relevância do presente se deve à necessidade do falante em situar o que é enunciado em relação ao sujeito que enuncia e em relação ao momento da fala. Essa proposta será desenvolvida, na terceira seção, a partir da discussão da noção de subjetificação que dispõe, na literatura, de três concepções diferentes. Com o intuito de preparar a utilização que faço da noção de subjetificação, exponho, na segunda seção, certos detalhes das análises de Fleischman $(O p$. cit.) e de Kurylowicz $(O p$. cit.), sobre a formação das perífrases de futuro e de passado, que esclarecem a dinâmica da expressão da modalização e da temporalização das formas verbais. Na terceira seção, discuto a relação entre as noçôes de relevância do presente e a noção de subjetificação a qual, na realidade, dispõe de três concepções na literatura. Após interrogação da razão da inovação linguística se vincular à de subjetificação, relaciono, na quarta seção, esta última com a noção de luta pelo reconhecimento, estabelecida na filosofia moderna. Na quinta seção, a título de ilustração da nossa proposta, analiso a formação, no português do Brasil, do fenômeno nomeado de gerundismo; nossa análise comprova o continuísmo da formação das perífrases verbais e atribui ao gerundismo o valor de um futuro próximo, o que é compatível com a relevância do presente apontada. Por fim, na sexta seção, apresento algumas palavras finais sobre as consequências da nossa reflexão para a teoria da gramaticalização.

\section{Temporalização e Modalização das Formas Sintéticas e Perifrásticas}

A análise da alternância e dos valores das formas de futuro tem uma longa história, com contribuições de vários autores. De acordo com Coseriu (1957), a substituição do futuro sintético pelas formas perifrásticas nas línguas românicas tem recebido dois tipos de explicações. 
A primeira delas - chamada de morfológica por Coseriu (1957, p. 1), mas que talvez, por razões que ficarão claras a seguir, seja mais bem nomeada como funcional - defende que o futuro simples foi substituído pelas formas perifrásticas, devido à heterogeneidade e às deficiências materiais das formas sintéticas. Nas palavras do autor

(...) en el latin 'vulgar' se confunden a menudo [w] y /b/ y con ello surge la confusión de las formas de futuro (amabit) con las de perfecto de indicativo (amavit). Por otra parte, el pasaje de $i$ a $e$ y la perdida de la cantidad vocálica llevan a molestas homofonias o casi-homofonias entre las formas de presente de los mismos verbos (dices - dicis,dicet - dicit) (COSERIU, Op. cit., p. 2). ${ }^{1}$

Tudo isso teria, segundo a hipótese morfológica, resultado na permuta entre o futuro sintético e as perífrases com habeo, debeo, volo, que seriam inequívocas. No fim das contas, a mudança se deve, como ficou claro, a razōes distintivas ou funcionais.

A segunda explicação, chamada por Coseriu de estilistica ou semântica, é atribuída a Vossler, mas, na realidade, foi proposta e desenvolvida antes, bem como depois desse autor. ${ }^{2}$ Com base nessa hipótese, de acordo com Coseriu (1957, p. 3),

(...) el futuro perifrástico se impuso debido al prevalecer de una particular actitud mental contraria a la idea meremente 'temporal' del futuro y favorable, en cambio, a otros valores, modales y afectivos: lo determinante habría sido pues, una necesidad expresiva para la que el futuro sintético del latín clásico resultaba inadecuado, no tanto por sus deficiencias formales como por su mismo contenido semántico (itálico do autor). ${ }^{3}$

Vejam, para efeito de documentação, a adoção da mesma ideia na conclusão de Mattoso Camara (1957, p. 224):

(...) a causa essencial da radicação do futuro romance foi a circunstância de que o valor exclusivamente temporal do futuro latino clássico se generalizou por intelectualização filosófica, enfraquecendo a sua coloração modal e levando a língua corrente a preferir locuçôes em que essa coloração fosse nítida. 
Coseriu combate a hipótese morfológica levando em conta dois argumentos: o primeiro deles é o de que, ainda que possa justificar a necessidade de substituir o futuro sintético, não explica o fato de essa forma ter sido substituída pela forma perifrástica e não por outro recurso qualquer; e o segundo apóia-se no fato de o futuro perifrástico, de orientação modal, não ser específico do latim vulgar, ocorrendo também nas línguas germânicas, no grego moderno, no servo-croata e em outras línguas. O autor reafirma, por isso, a pertinência da hipótese "semântica", ainda que a considere insuficiente, pois, para ele, a contínua substituição das formas de futuro não pode ser explicada pelo alegado "desgaste expressivo" da forma simples, já que o "desgaste" é exatamente o que se deve explicar. Portanto, segundo Coseriu, apelar para a gramaticalização é circular, já que é mera comprovação do que se sucedeu na língua. Ainda assim, o autor está de acordo com o que ele chama de universalidade da duplicidade do futuro, que oscila entre dois polos, ou seja, um puramente "temporal" e outro "modal" (incluídas nesse último as formas aspectuais). Essa visão dos fatos já aparecia na análise de Spitzer (1918), na qual a expressão do futuro se alterna entre o lógico e o afetivo: por um lado, o falante adota uma atitude subjetiva diante do futuro e expressa essa categoria por meio de formas modais, como requerido pela afetividade do sujeito; por outro lado, essas formas se gramaticalizam e se temporalizam como exigido pela lógica. Enfim, Coseriu propóe sua própria explicação para o fenômeno, procurando relacionar a gênese do futuro perifrástico ao momento histórico em que essa forma se implementou no latim vulgar, a saber, no momento da afirmação do cristianismo, que imprimiu uma nova dimensão subjetiva para a existência humana. Não vamos discutir aqui a relevância dessa última proposta de Coseriu (também desenvolvida por MULLER, 1945), mas preservaremos a intuição inicial sobre o tema no que se refere à alternância entre modalização e temporalização da expressão do futuro.

Um dos tratamentos contemporâneos do fenômeno, proposto por Fleischman (1982), mantém, assim, a constatação de que, acoplada a essa alternância de formas sintéticas e analíticas, ocorre, concomitantemente, alternância no que refere à expressão dos conteúdos de temporalidade e de modalidade das formas, de maneira que a quantidade de temporalidade ou de modalidade está sujeita a flutuaçôes. Quanto mais a forma expressar o conteúdo de tempo propriamente dito, menor é a sua força modal e vice-versa, ou seja, quando mais conteúdos modais forem expressos - como obrigação, volição, 
permissão, certeza, probabilidade... -, menos nítida é a expressão do tempo. Assim, quando a expressão da temporalidade se torna nítida, os falantes partem em busca de uma nova forma (no mais das vezes, perifrástica) que reponha a modalidade perdida no processo de temporalização.

A outra noção, intuída por vários autores, e capitalizada por Fleischman por meio da designação relevância do presente complementa a descrição do fenômeno, isto é, o tempo do auxiliar cooptado para compor a nova forma perifrástica é, normalmente, o tempo presente.

Damourette e Pichon (1936, p. 275) dão início à descrição do fenômeno da relevância do presente, estabelecendo que, com o futuro formado pelo verbo aller + infinitivo, a interpretação de futuro imediato ou eminente dessa forma perifrástica tem a ver, não com a proximidade cronológica do evento exprimido, mas com o "point de vue présent", levado em conta pelo falante. Com base nessa proposta, Fleischman (1982, p. 18) define a relevância do presente da seguinte maneira:

Present relevance: un aspectual notion signaling the establishment of a connection between "now" and "not-now"; a chronologically nonpresent (past or future) event is viewed as psychologically linked to present time. ${ }^{4}$

A noção de relevância do presente parece ter validade nas línguas em geral. Muitas delas dispóem, assim, de um futuro com o verbo equivalente a $\mathrm{ir}$, construção chamada de go-future por Fleischman, que é geralmente excluída das tabelas de conjugação verbal como uma expressão padrão do tempo futuro. Resta saber, em cada língua, se as formas perifrásticas têm ou não o mesmo valor das formas sintéticas ou se são funcionalmente equivalentes.

A relevância do presente é ilustrada, em português, pelo futuro com irchamado de futuro imediato por vários autores - e pelo processo de gramaticalização sofrido pelo verbo querer cujo conteúdo modal serve de fonte para o futuro (cf., entre outros, HOPPER; TRAUGOTT, 1993; VIANNA, 2000; LOBATO, 2010). Esse tipo de processo é comum em várias línguas, mesmo naquelas que não são indo-europeias, como em vários dialetos do árabe (cf. RUBIN, 2004). ${ }^{5}$ Observem, a seguir, os seguintes usos de querer, assim como do francês vouloir (volteios como (3) já foram atestados na Internet (cf. LOBATO, 2010): 
(3) tá querendo chover; tô querendo gripar;

(4) Il veut plevoir. (cf. JODOGNE, 1955)

Também nesse caso as formas do futuro têm sua fonte nas formas do presente, isto é, relacionam-se com o momento da fala. O verbo querer, nesse caso, indica probabilidade, o que foi viabilizado pelo esvaziamento do significado original de volição desse verbo. Em muitas descrições, a mudança semântica do presente em direção ao futuro encontra um contexto favorável que a justifica, devido ao fato de a forma original indicar uma obrigação ou desejo presente de agir e não uma ação presente.

Como dissemos, a relevância do presente é pertinente não apenas para a formação das perífrases de futuro mas também, como intuído por Jespersen, e desenvolvido por Kurylowicz, para a formação das perífrases que exprimem o passado.

Observem-se as palavras de Jespersen $(1931, \$ 4.1)$ :

The Perfect, which is composed by means of the present of an auxiliary, is itself a kind of present tense, and seems to connect the presente time with the past... The perfect is a retrospective present, which looks upon the present state as a result of what has happened in the past ${ }^{6}$ (itálico do autor).

É esta proposta que desenvolve Kurylowicz (1965) para o present perfect. Para apreciá-la, consideremos as duas construções abaixo:

(5) a. He has the book written.

b. He has written the book.

A estrutura em (5a), que precede, historicamente, a que se encontra em (5b), é analisada como a estrutura que serviu de "gatilho" para que have se tornasse auxiliar. Em (5a), a forma has é ainda interpretada como um verbo que indica posse e exprime, de acordo com a descrição de Kurilowicz (1965, p. 57), "le résultat d'une action antérieure accomplie sur un objet donné", 7 o que justificaria, segundo o autor, não ocorrer esse tipo de estrutura quando o objeto indica entidades, como "misfortunes" ou "words", que não podem ser objetos pré-existentes à ação verbal, ou, em outras palavras, são objetos que se constituem no ato da ação verbal. 
Houve, assim, uma mudança de significado: da primeira - (5a) -, que focaliza o estado que resulta de uma ação anterior, para a segunda - (5b) - que focaliza a ação anterior incluída no resultado desta ação. Essa mudança permite, como é de regra nos processos de gramaticalização, uma extensão deste tipo de construção para outros tipos de eventos. Em construções, por exemplo, he has lost the battle, o resultado obtido é "the lost of the battle", com valor de passado, e não mais a transformação sofrida por uma batalha pré-existente.

Em relação à interpretação da noção de tempo nesta mudança, ocorre ainda que a nuança de anterioridade em relação ao momento da fala toma mais relevo enquanto a noção de resultado de uma ação anterior perde intensidade.

As formas do simple past e do present perfect mantêm, no entanto, diferenças que as impedem ainda de serem usadas com o mesmo valor, como ocorre no caso do francês contemporâneo em que, como se sabe, o passé composé dispóe do mesmo valor que o passé simples. É interessante observar, no entanto, que, no francês clássico, nos séculos 17 e 18, a oposição entre as formas $j$ 'ai vu e je vîs é aproximadamente a mesma que existe entre I have seen e I saw no inglês contemporâneo.

De acordo, assim, com a descrição de Kurylowicz (1965, p. 59), a evolução da expressão do passado obedecerá às seguintes etapas:

$1^{\circ}$. estado presente (de algo realizado anteriormente);

$2^{\circ}$. ação anterior em relação ao momento da fala (com um resultado presente);

$3^{\circ}$. ação passada associada ao momento da fala (anterioridade); e $4^{\circ}$. ação passada.

Portanto, ainda segundo ele, a forma I have seen não chegou ainda à quarta etapa; diferentemente do caso do francês em que J'ai vu já se encontra no último estágio. Nas línguas que diferenciam o terceiro e o quarto estágios, como é o caso do italiano, o último estágio é sentido como um passado mais distante do presente: é o caso do passato rimoto, por exemplo, cantai, que se opóe a ho cantato.

O que importa reter aqui é que, como vimos em relação ao tempo futuro, a expressão do passado é alimentada correntemente pelas formas do presente, isto é, que se relacionam ao momento da fala, e a mudança é possível porque a forma original indica um estado presente resultado de uma ação passada (e não uma ação presente). Assim, uma vez que uma forma do presente é recrutada para 
exprimir o passado, ela trilhará uma evolução que a leva, gradativamente, a exprimir um passado sempre mais distante do presente.

Essa visão dos fatos é compatível com a trajetória da formação do auxiliar português ter em várias análises (cf, entre outras, COHEN, 1988; RIBEIRO, 1993; e VITRAL, 2006). Na nossa língua, a trajetória da forma ter é a mesma que ocorreu em inglês, francês e italiano, isto é, passou de verbo pleno a auxiliar e este processo teve como "gatilho" a mesma ordem de palavras que apontamos para o inglês. A nossa forma composta com o auxiliar no presente exprime, como se sabe, reiteração e continuidade que, segundo Ilari (1984, p. 185), "dizem respeito a um período que, começando no passado, alcança o momento da fala e eventualmente o ultrapassa". E como no caso do inglês, nossa forma composta com auxiliar no presente não alcançou o último estágio previsto por Kurylowicz, isto é, o da ação passada que pode, no entanto, ser expresso colocando-se o auxiliar no imperfeito. ${ }^{8}$

A conclusão de Kurylowicz é que é à situação do diálogo, que inclui o ponto agora do momento da fala, que os falantes devem sempre voltar não apenas para estabelecer o jogo das relaçóes temporais dos eventos mas também para criar formas do passado e do futuro. Nos termos de Fleischman, como vimos, tratase da relevância do presente.

Podemos agora recolocar as perguntas em (2), repetidas abaixo:

(6) a. a que se deve o fenômeno da relevância do presente?

b. que consequências teóricas esse fenômeno coloca em relação à perspectiva da gramaticalização?

Vamos desenvolver essas questóes na próxima seção, cotejando a relevância do presente, num primeiro momento, com a noção de subjetificação, e, num segundo momento, com a noção de luta por reconhecimento

\section{A Relevância do Presente e a noção de Subjetificação}

Com o intuito de explicitar o papel da noção de relevância do presente na inovação linguística, vamos considerar, inicialmente, a proposta de Lacey (1972, apud CORÔA (2005, p. 30), segundo a qual a dinâmica dos fatos do mundo biofísico, tal qual a língua os descreve, relacionando-os com o tempo, sugere uma prioridade ontológica do presente. É o presente, assim, que permite 
fazer a associação entre a teia dos eventos e a situação da enunciação definida pela relação entre o falante e o ouvinte; e o falante, ao tomar a palavra e se dirigir ao ouvinte, está sempre no ponto agora do eixo do tempo, relacionando tudo o que enuncia ao seu ponto de vista como sujeito. Vamos resumir essa descrição por meio da seguinte proposta:

(7) a partir do ponto agora do momento da fala, instalado na situação do diálogo, os falantes buscam se orientar, a fim de exprimir o jogo das relaçõos temporais dos eventos e também de criar formas do passado e do futuro.

Tomando por base ainda nossa descrição do papel do tempo presente na criação de formas perifrásticas, consideraremos que ocorre o seguinte estado de fatos: uma vez que uma forma do presente é cooptada para exprimir o passado ou o futuro, ela trilhará uma evolução que a leva, gradativamente, a exprimir um passado ou um futuro interpretado sempre como mais distante do presente. A inovação linguística obedece, assim, à seguinte dinâmica: visto que aquilo que deve ser enunciado pelo sujeito é, evidentemente, situado em relação ao tempo do evento, as formas de expressão do tempo, à medida que vivem sua evolução na língua, vão sendo interpretadas gradativamente como se reportando a eventos situados em tempos cada vez mais distantes do presente; para trazer a enunciação para o presente, o sujeito coopta itens que originalmente exprimem o presente e os faz instrumentos de expressão do passado e do futuro. As inovações provocam, portanto, a expressão de passados e futuros sentidos como mais próximos do presente.

Vejamos agora como articular a proposta resumida em (7) com a noção de subjetificação. A expressão do sujeito da enunciação é uma proposta desenvolvida, como se sabe, por Benveniste e explorada por diversos autores, de perspectivas teóricas diferentes, sob o nome de subjetividade ou subjetificação. Para explicitar essa noção, vamos considerar, em primeiro lugar, que há, três concepções de subjetificação, presentes na literatura, que estão entre nós há algum tempo, mas que, recentemente, foram um pouco mais sistematizadas pelos seguintes autores: 
(8) 1. o ponto de vista do falante (TRAUGOTT, 1995; TRAUGOTT; DASHER, 2005).

2. a expressividade do falante (OCHS; SCHIEFFELIN, 1989).

3. a perspectiva do falante (LANGACKER; 1990; 1991; 2000; 2006).

A noção de subjetificação sistematizada por Traugott (1995) e Traugott e Dasher (2005) compartilha propriedades com o conceito de modalização, sobretudo, a modalização de tipo epistêmica (cf. TRAUGOTT, 1995). Segundo os autores, "our prime concern is with subjectivity that explicitly encodes SP/ W's ['speaker/writer'] point of view, for example, in dêixis, modality, and marking of discourse strategies" (TRAUGOTT; DASHER, 2005, p. 21-22), ou seja, trata-se de fenômenos de linguagem que dizem respeito à avaliação subjetiva em relação à aquilo que é dito.

Entre os fatos de linguagem que interessam à perspectiva de subjetificação como ponto de vista do falante, pode-se incluir ainda - já que se trata dos recursos de natureza pragmática que refletem a avaliação feita pelo falante da fonte da informação relatada - o interessante fenômeno dos evidenciais ('evidentials'), que têm sido analisados, mais recentemente, numa perspectiva formalista que leva em conta a proposta de Rizzi $(1997 ; 2004)$ acerca da estrutura de categorias sintáticas à esquerda da sentença (cf. HILL, 2007; SPEAS, 2004).

A noção de subjetificação que chamei de expressividade do falante, capitalizada por Ochs e Schieffelin (1989), é bastante promissora em relação à busca de fundamentação para o fenômeno de inovação linguística. A distinção entre as funçôes emotiva ou expressiva e referencial / conotativa da linguagem tem sido apontada, pelo menos, desde Sapir (1968), Bühler (1934) e Jakobson (1960), mas, como se sabe, é, ainda hoje, relegada a segundo plano, já que foge do escopo de fenômenos que interessam aos paradigmas dominantes da nossa área; mas há, atualmente, alguma renovação do interesse pela função emotiva da linguagem em perspectivas teóricas distintas (cf. PLANTIN, 2011).

De nossa parte, o interesse pela subjetificação na perspectiva da expressividade do falante se justifica na medida que se destacam, como objeto de reflexão, os recursos da linguagem que permitem aos falantes exprimir conteúdos afetivos que podem levar formas com determinado uso normalizado a serem convertidas em formas de uso inovador. Assim, há diferenças entre os fenômenos mirados pela perspectiva de subjetificação sistematizada por Traugott 
e aqueles de interesse da perspectiva da expressividade do falante. Naquela perspectiva, tomando como exemplo a evolução dos verbos modais em várias línguas que, de significado concreto / agentivo, passam a exprimir conteúdo abstrato / epistêmico, é privilegiada a conversão de conteúdos referenciais em conteúdos subjetivos que necessitam de maturação cognitiva na comunidade de fala, sendo preciso, muitas vezes, de alguns séculos para que se consolide (cf. LIGHTFOOT, 1979).

Os fenômenos de interesse da perspectiva da expressividade do falante parecem ser, por outro lado, de natureza diferente dos apontados por Traugott e Dasher, já que se ligam à subjetividade do falante de maneira, digamos, mais imediata. Refiro-me ao fato de que, levando em conta a motivação emotiva ou expressiva do falante, as formas geradas a partir daí refletem de maneira imediata e individual a subjetividade do falante e permanecem disponíveis de maneira automática.

A título de exemplificação, estamos pensando em fenômenos que envolvem os juízos que os falantes enunciam nos quais eles lidam com noçóes como intensidade, quantidade, tamanho, distância, o certo e o errado, e o belo e o feio, etc. Bem entendido, são juízos por excelência reveladores da subjetividade do falante e se prestam, sobremaneira, à inovação. Pode-se dividi-los da seguinte maneira:
a. juízos estéticos (belo / feio);
b. juízos de qualificação (grande / pequeno, perto/longe, cedo / tarde, etc.);
c. juízos de quantidade (muito / pouco);
d. juízos morais (bom / mau);
e. juízos de valor (bom / ruim).

Vou chamá-los de juizos de gradação (cf. SAPIR, 1968). Propomos também que os juizos de gradação se opõem aos juízos de existência. A diferença central é que, nos juízos de existência, há uma pretensão de veracidade, ou falsidade, em relação ao que é dito, mas no caso dos juízos de gradação é diferente: é uma avaliação subjetiva do falante acerca do que é dito que implica gradação. Por exemplo, se um falante diz: "João mora longe pra dedéu, pra capeta ou pra caralho", "9 ele traz intensidade em relação à distância, mas é uma avaliação pessoal e relativa às referências do falante. 
O espraiamento e a consolidação de uma forma inovadora criada nesse contexto com as motivações que explicamos dependerão, evidentemente, de outros aspectos, por exemplo, as redes sociais de que participa o falante e seu papel dentro delas, determinado pela natureza das identificações dos membros das redes com o falante. No entanto, não nos ocuparemos desses aspectos neste trabalho (cf. MILROY, 1980; BORTONI-RICARDO, 2011).

A noção de subjetificação que coloca em jogo a função expressiva ou emotiva parece, por outro lado, poder dizer algo acerca da inovação do ponto de vista lexical. Uma das questões a ser explorada, mas que também não faremos aqui, é a de investigar em que medida seria também relevante para a inovação do ponto de vista gramatical, o que implica examinar os "gatilhos" da mudança que permitem a migração de acepções léxicas para acepções gramaticais com a consequente mudança da classe dos itens envolvidos. Nesses processos, como se prevê, ao mudar-se a classe do item que entra no componente sintático, geramse produtos gramaticais distintos.

Comentemos, por fim, a concepção de subjetificação de Langacker que tem sido elaborada, como se viu, em certo número de textos. De início, esse autor dá destaque à noção de fundo ("ground"), definida como o evento de fala que inclui a interação entre o eixo objetivo dos participantes do evento e o eixo subjetivo do falante (cf. também NARROG, 2010). Pode-se vislumbrar sua concepção a partir dos seguintes exemplos:

(10) a. Vanessa is sitting across the table from Veronica.

b. Vanessa is sitting across the table from me.

c. Vanessa is sitting across the table.

Em (10a), Veronica, um participante do evento objetivamente estabelecido, serve como um ponto de referência para a localização de Vanessa, outro participante objetivamente estabelecido. Em (10b), o fundo é envolvido na conceptualização, já que o falante, um participante do evento, funciona como ponto de referência para a localização de Vanessa; a diferença de (10b) para (10c) é que, nesta, o falante continua sendo ponto de referência, mas não há forma que o expresse, sendo estabelecida a referência de maneira subjetiva.

Ainda para Langacker, porém, uma expressão ou seu significado, tomada de forma conjunta, não é inerentemente objetiva nem subjetiva, o que dependeria, na realidade, da elaboração dos falantes que construiriam seu significado com 
maior ou menor grau de subjetividade ou objetividade (cf. LANGACKER, 2006, p. 18). Ele insiste ainda numa certa atenuação ('attenuation') do grau de controle exercido pelos falantes na construção de expressões mais subjetivas que implicam, assim, uma conceptualização implícita ou tácita sem que a consciência seja exercida (2000, p. 297).

Pensemos agora, a fim de concluir esta seção, a respeito da articulação entre a noção de subjetificação e a relevância do presente apontada na segunda seção. Resumimos nossa descrição do fenômeno da relevância do presente por meio da generalização em (7), repetida abaixo:

(11) A partir do ponto agora do momento da fala, instalado na situação do diálogo, os falantes buscam se orientar, a fim de exprimir o jogo das relações temporais dos eventos e também de criar novas formas do passado e do futuro.

A generalização acima pode ser articulada com a noção de subjetificação de acordo com a perspectiva de Langacker. Vamos propor que a relevância do presente deve ser atribuída ao papel da subjetividade ao balizar a expressão do falante nas interações discursivas: assim como a localização espacial do falante serviu como referência que determinou sua expressão no exemplo (10c) acima, diremos que o tempo presente é mais um dos elementos da linguagem que funciona como um tipo de "eixo", conectando a enunciação e o sujeito, o que determina aspectos de forma das escolhas dos falantes.

A inteligibilidade do fenômeno da inovação linguística e sua relação com a subjetificação podem ainda ser exploradas na seguinte direção: é preciso examinar a razão de a subjetividade do falante, colocada em jogo pelo tempo presente, servir de "motor" para a inovação linguística. Para desenvolver um pouco esse aspecto, apresento, na próxima seção, uma discussão, bastante resumida, sobre a noção de luta por reconhecimento.

\section{A Subjetificação e a noção de Luta pelo Reconhecimento}

Para desenvolver a questão colocada, partiremos da seguinte intuição: o sujeito da enunciação, ao trazer a descrição dos eventos para o presente, busca, ser expressivo para um outro que é visado. 
Tendo em mente a criação das formas perifrásticas tal qual descrito acima, tentemos explicitar nossa proposta: tudo se passa como se o fato de reportar-se a eventos narrados em tempos cada vez mais distantes do presente afetasse a credibilidade daquilo que é enunciado e, em última instância, a própria credibilidade do enunciador. Nessa afirmação, há muitas possibilidades de articulação com aspectos de linguagem que o próprio leitor pode vislumbrar. De minha parte, proponho construir a inteligibilidade do fenômeno tal qual descrito até aqui por meio da noção de luta por reconhecimento. "Ser expressivo", como apontamos acima, é, então, buscar o reconhecimento do outro, ou, em outras palavras, à medida que produzimos atos de fala, visamos a obter algo que, em última instância, éo próprio reconhecimento pelo outro do nosso estatuto como sujeito.

Assim, a questão colocada no final da seção anterior encontra o seguinte caminho de resposta: a enunciação é centrada no sujeito, por meio do instrumento do tempo presente, para habilitar o sujeito a desempenhar seu papel na luta pelo reconhecimento.

A fundamentação da noção de reconhecimento tem certa história na filosofia social moderna e tem como principais referências as contribuiçôes de Maquiavel em O Príncipe (1513 (1983)), de Hobbes em Leviatã (1651 (1983) e de Hegel em System der Sittlichkeit (1893 [1992]). No século 20, a ideia de que o sujeito deve sua identidade a uma experiência de um reconhecimento intersubjetivo foi desenvolvida, com uma preocupação mais objetiva e empírica, pelo psicólogo social George Mead (1934 (2006)) no livro Mind, Self and Society from the Standpoint of a social Behaviorist, e, contemporaneamente, podem-se ler reflexōes sobre o tema nos livros Luta por Reconhecimento. A gramática dos conflitos morais do filósofo alemão Axel Honneth (2003) e Parcours de La Reconnaissance de Paul Ricoeur (2004). Vejamos a seguir, em suas grandes linhas, um brevíssimo histórico sobre essa noção.

\subsection{Pontos Centrais da História da Noção de Reconhecimento}

Os escritos de Maquiavel preparam o terreno para o desenvolvimento da ideia segundo a qual as relações entre os indivíduos se estabelecem numa concorrência permanente de interesses. Com Hobbes, essa ideia se torna a base de uma teoria do contrato social que fundamenta a atuação dos Estados. Esses autores rompem com as idealizaçôes da mentalidade clássica e da mentalidade cristã que pensavam o homem como um animal político que dependia de um 
quadro social de uma coletividade política para realizar sua natureza interna na busca virtuosa da polis ou da civitas, ou seja, com a finalidade de satisfazer necessidades de várias naturezas seríamos, segundo a concepção clássica, impelidos a nos organizar e a viver de forma cooperativa com os outros (cf. ZAGORIN, 2009, p. 6-11). Maquiavel abandona essa concepção ao conceber o homem como um ser egocêntrico, que busca sobrepujar os outros indivíduos, o que estabelece uma concorrência hostil impelida pela estratégia constante de realizar açôes ou produtos sempre vencedores ou coroados de êxito. De acordo com Honneth (2003, p. 37), Hegel herda dos dois autores o modelo conceitual de uma luta social entre os homens e parte da ideia de que uma teoria filosófica da sociedade deve considerar, como um tipo de base natural da socialização humana, um estado que essencialmente se define pela existência de formas elementares de convívio intersubjetivo. Além disso, Hegel se ocupa de explicar de que maneira passamos de um estado de "eticidade" natural para uma organização social estruturada pela totalidade ética. Essa organização social se molda na história, de forma processual e constante, por meio de desequilíbrios entre os indivíduos que são causados pela luta de cada um com vistas à imposição de suas pretensões e particularidades. Nesse processo, a coesão orgânica da sociedade se estabelece a partir do "reconhecimento intersubjetivo da particularidade de todos os indivíduos" (HONNETH, 2003, p. 45). A estrutura da relação de reconhecimento recíproco, de acordo com interpretação de Hegel proposta por Honneth, se estabelece da seguinte maneira: na medida que se sabe reconhecido por um outro sujeito em algumas de suas capacidades e propriedades e nisso está reconciliado com ele, um sujeito sempre virá a conhecer, ao mesmo tempo, as partes de sua identidade inconfundível e, desse modo, também estará contraposto ao outro novamente como um particular. E os sujeitos "vêm sempre a saber algo mais acerca de sua identidade particular, pois trata-se em cada caso até mesmo de uma nova dimensão de seu Eu que veem confirmada” (HONNETH, 2003, p. 45). Isso se estabelece na medida que os sujeitos abandonam a cada momento

a etapa da eticidade alcançada, também de modo conflituoso, para chegar de certa maneira ao reconhecimento de uma forma mais exigente de individualidade; nesse sentido, o movimento de reconhecimento que subjaz uma relação ética entre sujeitos consiste num processo de etapas de reconciliação e de conflito..., as quais substituem umas às outras. (HONNETH, 2003, p. 47). 
Assim, subjacente a esse processo, encontra-se o modelo da luta pelo reconhecimento, que se constitui, como se disse, numa disputa entre sujeitos, cujo objeto é constituído pelo reconhecimento de suas pretensóes ou pela busca de honra, vista como uma afirmação do próprio sujeito. Nessa perspectiva, consideraremos, por fim, que uma transgressão da norma, ou de um preceito ético, pode ser vista como uma tentativa de ampliar uma etapa ética estabelecida e, uma vez reconhecida e incorporada à totalidade ética, terá como consequência permitir atribuir ao sujeito o caráter de inovador.

Reelaborar a noção de luta por reconhecimento a partir do racionalismo contemporâneo foi uma tarefa levada adiante por Mead (2006), no século 20. Ele também procura fazer da luta por reconhecimento o ponto referencial de uma construção teórica que visa a explicar a evolução moral da sociedade, mas com uma base empírica. ${ }^{10}$

É-nos importante apontar as linhas gerais da proposta de Mead porque é a partir daí que vamos refletir a transposição dessas ideias para o fenômeno da inovação linguística e da centralidade da subjetividade nesse processo.

Mead tenta inicialmente compreender como se dá a formação do subjetivo e da consciência do eu. Como outros também disserem, por exemplo, Benveniste (1976, p. 286), para quem a consciência de si mesmo só é possível se experimentada por contraste, isto é, "eu não emprego $e u$, a não ser dirigindo-me a alguém que será na minha alocução um tu [ou você]", Mead admite que um sujeito só pode adquirir uma consciência de si mesmo à medida que ele aprende a perceber sua própria ação da perspectiva, simbolicamente representada, de uma segunda pessoa. Há, assim, uma precedência da percepção do outro sobre o desenvolvimento da autoconsciência. Após isso, Mead se preocupa em como se estabelecem, advindas da relação com o outro, as noçōes morais que introjetamos. Ele propõe uma ideia, também desenvolvida por autores de horizontes teóricos distintos, ${ }^{11}$ que as normas sociais que adquirimos vêm a partir do outro: é a partir do que supomos que o outro aprova ou desaprova que formamos nossas normas morais internas. Mead chama isso de "outro generalizado". Assim, à medida que a criança em desenvolvimento reconhece seus parceiros de interação pela via da interiorização de suas atitudes normativas, ela própria pode saber-se reconhecida como um membro de seu contexto social de cooperação. Ocorre, assim, a inclusão e a adequação do sujeito num grupo ou numa comunidade. Mas há, por outro lado, uma impulsividade que leva o sujeito a divergir das normas sociais, buscando 
se satisfazer individualmente e reivindicando, na sua comunidade, a legitimidade de seus desejos como indivíduo, ou, em outras palavras: o sujeito procura constantemente ampliar as normas de maneira a conferir expressão social à impulsividade e à criatividade do seu eu. ${ }^{12}$ Enfim, haverá sempre, no sujeito, uma tensão entre a vontade da comunidade internalizada por meio de normas $\mathrm{e}$ as pretensōes de individuação, o que é o motor da criatividade.

Desenvolver essas ideias em profundidade exigiria explicitar o papel da noção de identificação e de suas implicações na formação do aparelho psíquico e está fora dos nossos objetivos neste artigo; ${ }^{13}$ e como se dá a implementação social das inovaçôes, ${ }^{14} \mathrm{o}$ que igualmente não faremos aqui.

Vejamos, porém, ainda que de forma bastante incipiente, como transplantar essas ideias para o campo da inovação linguística. A questão que nos interessa é a seguinte: como pensar a evolução social, no sentido de Mead e sua projeção, consequências ou implantação na evolução da língua, ou, em outras palavras, como é implementada a correspondência entre mecanismos de organização individual e social e a evolução da língua. Essa questão é, evidentemente, bastante ampla e exige um trabalho de muito fôlego para ser desenvolvida de forma minimamente satisfatória. O que vamos propor é apenas uma direção para essa reflexão, supondo que é possível pensar a inovação linguística, que ocorre nos processos de gramaticalização e de lexicalização, como uma afirmação do $e u$, o que pode implicar uma transgressão normativa no sentido de Mead. Vejamos mais alguns detalhes sobre essa ideia.

\subsection{A Inovação Linguística e a noção de Reconhecimento}

Considerando que a linguagem é constitutiva do sujeito, é a partir dessa condição que o falante pode se tornar, como dissemos, um sujeito que busca ser expressivo para o outro. Ser expressivo tem como pré-condição a constituição do sujeito, mas vai além disso, relacionando-se com a concepção de reconhecimento. Ser expressivo é, então, buscar, na medida que produzimos atos de fala, algo do outro que, essencialmente, é o próprio reconhecimento pelo outro.

A nossa proposta é que a inovação linguística, centralizada pela subjetividade, é gerada no contexto da busca de reconhecimento. Essa proposta pode muito bem ser um início de um desenvolvimento da intuição de Meillet, no texto inaugural sobre a gramaticalização, de 1912, quando ele propõe que os fenômenos de gramaticalização resultam da tensão entre a expressividade e a 
frequência de uso das formas da língua por parte dos falantes, ou seja, à medida que a frequência de uso aumenta uma dada forma perde expressividade. Nos nossos termos: à medida que uma dada forma se espraia na língua e a frequência de uso aumenta, ela reduz sua capacidade de ser um trunfo na luta por reconhecimento por parte de um sujeito. Assim, formas inovadoras são criadas pelos falantes de maneira a reaver a capacidade de ser trunfo na luta por reconhecimento que se reduz, ou é perdida, pelas formas conservadoras. Mas, é importante demarcar-nos da perspectiva da semântica argumentativa no sentido de que a inovação linguística não é um processo consciente no qual o sujeito tem pretensão à verdade, construída simbolicamente por atos argumentativos. No nosso caso, o falante não pretende superar o interlocutor ao criar uma inovação, e sim apenas ser reconhecido no seu papel social daquela interação e, possivelmente, nem toda violação da norma teria esse papel, e sim só aquelas que inovam do ponto de vista expressivo.

A adaptação dessa proposta ao caso de gramaticalização implica considerar ainda que, ao haver desgaste de uma forma, descrita por sua redução fônica e semântica, ela diminui sua capacidade expressiva, o que quer dizer que ela reduz sua capacidade de ser usada por um sujeito constituído na luta por reconhecimento.

Vamos aliar a proposta acima com a nossa descrição acerca da relevância do presente enunciada em (7). Como vimos, trazer o enunciado para o agora da enunciação e, como consequência, para o sujeito é o mecanismo que deflagra a criação das formas inovadoras que compóem as formas perifrásticas. Podemos considerar, assim, que as formas conservadoras, ao descreverem eventos cada vez mais distantes do presente, perdem seu valor expressivo, o que reduz sua capacidade de ser trunfo na luta pelo reconhecimento; as formas inovadoras, que, como vimos em relação às formas perifrásticas, se fundam a partir de conteúdos modais -, trazem a descrição dos eventos para o presente e recuperam valor expressivo que as capacita a ser trunfos na busca de reconhecimento. Portanto, o valor expressivo é reinstalado à medida que, ao trazer a descrição dos eventos para o presente, é recolocado o sujeito enunciador na luta pelo reconhecimento.

Com o intuito de ilustrar as ideias propostas, analisaremos, na próxima seção, uma forma perifrástica inovadora do português brasileiro atual que é o chamado gerundismo. 


\section{A Relevância do Presente e o Gerundismo}

Como apontamos no início deste artigo, a formação de perífrases verbais é um processo contínuo e cíclico e parece estar em atuação quando se observa o chamado gerundismo do português do Brasil atual. Como se sabe, o gerundismo é a perífrase formada pelo verbo estar + verbo no gerúndio em contextos nos quais, aparentemente, não há significado de concomitância de ocorrência de eventos, como previsto pelos usos já normalizados da perífrase formada por essa estar + verbo no gerúndio. Trata-se, por exemplo, de usos como os seguintes:

(12) Posso estar enviando o cartão para o senhor?

A fim de podermos apreciar o fenômeno do gerundismo na perspectiva que nos interessa, precisamos considerar, em primeiro lugar, que a condenação dessa forma por aqueles que se atribuem papel normativo se deve ao fato de, morfologicamente, tratar-se de uma perífrase que indica aspecto durativo, mas que é empregada num contexto sintático e semântico que não permite a interpretação desse aspecto. Entretanto, como veremos logo abaixo, essa perífrase, de fato, na sua versão mais inovadora, não exprime aspecto durativo, e sim é uma nova forma de futuro próximo. ${ }^{15} \mathrm{Na}$ nossa análise, portanto, o mecanismo subjacente à gênese de perífrases verbais continua atuante e, ao criar a perífrase verbal com o acréscimo do auxiliar estar, os falantes recuam a narração do tempo de um evento futuro para o presente, gerando uma nova forma de futuro próximo. Em segundo lugar, será necessário distinguir o ponto de vista da recepção do ponto de vista da produção dessa perífrase. Em relação ao primeiro aspecto, o da recepção, o gerundismo tem sido tomado como um não compromisso do falante com o que é dito. Vejam-se nessa direção as palavras de Possenti (2005, p. 10):

De quebra, a fórmula é também menos comprometedora: se uma empresa diz que enviará, você pode esperar pelo produto; se disser que vai entregar, duvide um pouco, mas se disser que vai estar entregando, desista... (itálicos do autor)

Essa visão nos parece equivocada, já que não pode corresponder ao ponto de vista do falante que produz a forma, a não ser que tenhamos de supor uma perversidade inerente do falante do $\mathrm{PB}$ (português brasileiro) que teria a intenção de ludibriar seu interlocutor e escolhesse, de maneira mais ou menos consciente, determinadas formas para alcançar tal finalidade. Não quero negar que, com o 
espraiamento da forma, tenha ocorrido mesmo essa recepção, ou seja, a impressão de "enrolação" é uma avaliação de quem recebe a forma, mas quero negar que exista, de fato, essa intenção do ponto de vista do falante que produz a forma. Para esse ponto ficar mais claro, vamos tomar como possível, mas discutiremos esse ponto um pouco mais logo abaixo, a alegada origem ou forte presença da perífrase nos meios de telemarketing: não precisamos discutir agora a controversa origem da nossa perífrase como um empréstimo do inglês, mas a presença, pelo menos, da forma nesses meios comerciais nos leva a pensar que o falante que a produz quer vender seu produto e o que quer alcançar, portanto, é a credibilidade de quem o escuta. Quando o operador de telemarketing diz então: vou estar enviando a encomenda para o senhor, o que ele quer é que o interlocutor tenha confiança de que receberá a encomenda o quanto antes e, para isso, aos olhos desse operador / falante, ele escolheu, provavelmente, de maneira inconsciente, a forma considerada mais polida ou culta de que dispóe. O departamento de entrega da empresa pode ou não entregar a encomenda no prazo acordado e o cliente / ouvinte, caso a encomenda nunca chegue ou não chegue no prazo previsto, pode vir a associar o uso do gerundismo à falta de compromisso do vendedor / falante, mas a relação entre esses dois aspectos transcende a perspectiva da produção da forma. Reafirmamos, assim, que a interpretação de que o uso do gerundismo implica falta de compromisso do falante diz respeito à recepção da forma, e não à sua produção. Ainda sustenta essa percepção dos fatos o caso em que, quando o gerundismo é usado fora do contexto de vendas, não há percepção do ouvinte de que há tentativa de enganá-lo e quem emprega essa forma, na verdade, julga que está usando uma forma de prestígio.

É provável, assim, que a forma conhecida por gerundismo tenha sido empregada, de início, com o intuito de passar ao ouvinte o compromisso do falante com a realização do que é dito na proposição. Considerando agora a formulação de que modo pode se realizar na forma verbal como representação da posição subjetiva do falante em relação ao que é dito (cf. BYBEE, 1985; HEGENVELD, 2010), faremos a suposição de que, na primeira etapa da formação do gerundismo, veiculou-se uma noção de modalidade orientada para o agente, visto que se exprime desejo, dever ou obrigação (cf. FONSECA, 2010; SILVA, 2002)

Em seguida, com a evolução do gerundismo na língua, este adquiriu, na sua causalidade interna e na perspectiva de sua produção pelo falante, valor de futuro próximo. Nessa proposta, não vou me preocupar com o cotejamento do uso do 
gerundismo com variáveis sociais, tais como que classe(s) o utiliza(m), que ramo profissional, etc., nem com que frequência ocorre de acordo com tais variáveis; vou me ater, exclusivamente, à causalidade interna da perífrase, ou seja, ao sistema modal / aspectual / temporal do PB que necessitou de criar a perífrase com valor de futuro próximo; e a criação de perífrases, como vimos acima, é fenômeno de linguagem natural e esperado. Nada impede, porém, que o cotejamento supramencionado mostre a origem ou a afinidade social da forma ou mesmo a inter-relação entre esses aspectos e o espraiamento da inovação; mas, no nosso modo de ver, ela não teria lugar, mesmo admitindo essa causalidade externa, sem a necessidade interna do sistema modal / temporal / aspectual da língua.

De acordo com a nossa proposta, portanto, a forma vou estar enviando a encomenda para o senhor é diferente de enviarei a encomenda para o senhor, que nos parece um futuro bem mais remoto do que vou estar enviando; entre as duas formas, encontra-se, bem entendido, a forma vou enviar. É nesse sentido que o gerundismo surge como um novo futuro próximo, de maneira que dispomos, pelo menos em princípio, da seguinte gradação: enviarei é o futuro mais distante do presente; vou enviar é mais próximo do presente do que enviarei, mas é mais distante do presente do que vou estar enviando, que é então o futuro mais próximo do presente. Essa suposta gradação parece se neutralizar, no entanto, quando se observa o comportamento contemporâneo da forma sintética do futuro e da forma perifrástica com ir: trabalhos recentes têm mostrado que essas duas formas se tornaram variantes sendo empregadas com o mesmo valor de verdade e sem nuanças modalizadoras; observa-se tão somente uma preferência considerável da perífrase com ir na fala e alguma produtividade, tendendo fortemente à redução, o que dependerá dos gêneros textuais, da forma sintética na escrita (cf. FONSECA, 2010; SILVA, 2002).

$\mathrm{O}$ fato de a forma perifrástica de futuro com ir já, praticamente, se equivaler à forma sintética pode também servir como argumento para a necessidade do sistema modal / aspectual / temporal do PB ter dado início à inovação do gerundismo com valor de futuro próximo. Vejamos, a título de ilustração, alguns exemplos do gerundismo com o valor alegado:

(13) Andréa vai agora estar conversando com vocês no chat do Big Brother. (Fala do jornalista Pedro Bial na eliminação de um dos participantes do programa Big Brother Brasil, exibido pela Rede Globo de televisão) 
(14) O orçamento é de 3 a 7 dias, mas de qualquer forma eu vou tá ligando para a senhora e passando o valor.

(Fala de uma atendente de uma loja de conserto de eletro-eletrônicos)

(15) Outra vacina que vamos estar aplicando amanhã.

(Fala do ex-Ministro da Saúde José Serra. Entrevista ao Jornal Nacional em 2001)

(16) Neste trabalho, vamos estar abordando aspectos referentes ao gênero diário. (oração de redação de aluno de ensino superior)

Como se vê, o conteúdo asseverativo da proposição é provavelmente a fonte modal que parece estar na base da interpretação de futuro próximo dessas construções.

O contraste entre as orações seguintes reforça ainda nossa análise:

(17) a. você assinará o contrato cinco anos depois de quitada a casa

b. você vai assinar o contrato cinco anos depois de quitada a casa.

c. ?* você vai estar assinando o contrato cinco anos depois de quitada a casa

(18) a. Meu time será campeão um dia.

b. Meu time vai ser campeão um dia.

c. * Meu time vai estar sendo campeão um dia.

(19) a. Haverá muita encomenda neste natal.

b. Vai haver muita encomenda neste natal.

c. ?* Vai estar havendo muita encomenda neste natal.

A estranheza das orações (17c),(18c),e (19c) se deve, a nosso ver, à incompatibilidade do gerundismo com a previsão de acontecimentos em eventos distantes do presente. Poder-se-ia alegar, por outro lado, que a má-formação dessas construçôes se deve não ao valor de futuro próximo que identificamos, e sim ao fato de que, nos casos de o evento ser pontual, como em (18), haveria incompatibilidade com o aspecto durativo do gerundismo, que ainda subsistiria residualmente. Contrário a essa versão dos fatos, devo apontar que o gerundismo pode não contribuir, na realidade, com a interpretação de aspecto durativo, 
mesmo que residualmente, como os exemplos (13-16) o mostram. Além disso, mesmo quando o evento é determinado por um verbo não pontual, o uso do gerundismo provoca estranheza quando aparece um modificador projetando o evento para um futuro remoto:

(20) a.*? Física quântica é difícil, mas eu vou estar aprendendo esse assunto um dia desses.

Física quântica é difícil, mas eu vou aprender / aprenderei esse assunto um dia desses.

(21) a. ? Aquela criança não consegue andar com esse aparelho, mas vai estar andando um dia desses

Aquela criança não consegue andar com esse aparelho, mas andará / vai andar um dia desses.

(22) a. *? Eu não consegui conhecer Paris bem, mas vou estar conhecendo na próxima viagem.

Eu não consegui conhecer Paris bem, mas vou conhecer / conhecerei na próxima viagem.

Por fim, o gerundismo torna as orações mal formadas quando aparece em orações condicionais ou temporais nas quais, como se sabe, se faz presente o chamado futuro do subjuntivo:

(23) a. *?Se você for estar viajando no próximo ano, não esqueça de visitar sua tia.

b. Se você for viajar / viajar no próximo ano, não esqueça de visitar sua tia.

(24) a. ?Quando você for estar viajando no próximo ano, não esqueça de visitar sua tia.

b. Quando você for viajar / viajar no próximo ano, não esqueça de visitar sua tia.

Assim, a má formação dos exemplos (23a) e (24a) se deve ao fato de que, nas oraçôes temporais e condicionais, a realização do evento é remota ou introduz probabilidade, o que é incompatível com o valor de futuro próximo do gerundismo. Parece, portanto, que o fato de o verbo ser pontual ou não pontual não é o fator determinante na boa formação das construções com o gerundismo. 
O valor de futuro próximo do gerundismo é estabelecido, por outro lado, independentemente da presença do auxiliar $i r$. Observem-se os seguintes exemplos:

(25) a. Quando estiver num país estrangeiro, é bom interagir com a população local.

b. Quando estiver num país estrangeiro, é bom estar interagindo com a população local.

A comparação de (25a) com a ocorrência de gerundismo em (25b) garante que o valor de futuro independe da presença do auxiliar ir e nos sugere, igualmente, que o valor durativo original do gerúndio com estar, visto que prolonga a ação verbal do presente para o futuro, pode ter sido o "gatilho" que permitiu gerar nossa forma inovadora. A confirmação dessa possibilidade de análise dependerá, evidentemente, de uma pesquisa ampla que considere certo número de dados e que investigue também outro aspecto interessante desse conjunto de fenômenos que é o fato de que estar parece concorrer com ficar, pelo menos em alguns contextos, como os que são apresentados a seguir, retirados do corpus PEUL/UFRJ, dados de 1980:

(26) Ah! Minha avó é gosta muito mais de se divertir, gosta tomar cerveja dela. Cerveja ela toma bastante! Gosta de samba, minha mãe também, mas minha mãe agora está um pouco devagar, porque ela esteve doente, então,(hes) não pode mais trabalhar, não pode mais estar se divertindo (inint) ("se") divertia antes...

(27) ...se ela tivesse dúvida de alguma coisa, chega perto de mim, sabe? se eu souber, eu explico, eu falo, sabe? não É esse negócio de estar prendendo, que eu fui muito presa, sabe? não tinha liberdade para nada, sabe? mas prender [não]...

(28) ...eu pagar um salário mínimo à empregada para minha mulher ficar batendo perna na rua, (barulho de moto) não é interessante, certo? só para dizer que está empregada, para dizer que está trabalhando fora, em vez de estar ajudando o marido, está prejudicando, não é interessante. e hoje em dia emprego de cem mil cruzeiro não está fácil de arranjar, certo?... 
Nesses exemplos, observa-se que a construção com estar + verbo no gerúndio poderia ser substituída por uma construção com apenas o verbo no infinitivo ou, mantendo-se o gerúndio, ser substituída por uma construção em que se trocasse somente o verbo estar pelo verbo ficar. Dados como esses, de trinta anos atrás, sugerem que pode ter havido, ou estar havendo, um processo de variação entre estar e ficar de maneira que a introdução de estar nos contextos de valor durativo, estabelecidos por ficar, pode também ter contribuído para criar um contexto favorável ao surgimento do gerundismo, que, aliás, segundo os trabalhos de Menon (2008) ${ }^{16}$ e de Possenti (2005), é uma construção perfeitamente vernácula. Como disse, não explorarei essas possibilidades de análise neste trabalho, mas, caso se confirme, mostraria que o uso do gerundismo no ambiente do telemarketing tem mais a ver com o espraiamento da construção, com o valor modal que apontamos, do que com sua origem por empréstimo do inglês.

\section{Considerações finais}

Vejamos, por fim, como resumir algumas das ideias apresentadas aqui, tendo como finalidade adicional a busca de fundamentação da teoria sobre os processos de gramaticalização.

Propomos que a compreensão das justificativas da inovação linguística passa por uma cadeia de causalidade que apresenta as seguintes dependências:

- relevância do presente > subjetificação > luta por reconhecimento.

A articulação desses conceitos que realizamos, se for adequada, pode também ser recebida como uma articulação interpretativa das causas de, pelo menos, certos tipos de processos de gramaticalização e colabora para a confirmação do papel da noção de subjetificação nesses processos, já alegada, como vimos, na literatura.

Considerando ainda que o nosso objetivo central é contribuir com a fundamentação da teoria da gramaticalização, um caminho produtivo é, a partir da cadeia de causalidade proposta, constituir uma teoria autônoma e empírica da gramaticalização, estabelecendo possibilidades preditivas, o que, em parte, já é realizado na literatura sobre o tema. Nesse sentido, necessitamos de explicitar nosso objeto de estudo e de prever que fenomenologia interessará a nossa teoria e ainda que recursos descritivos colocar em uso para tratar desses fenômenos. 
Podem-se desenvolver essas propostas tomando por base que o objeto dessa teoria é o seguinte:

(29) A descrição dos processos de formação dos arranjos sintáticos a partir das inovações por que passam, diacronicamente, os itens do léxico.

No que concerne à fenomenologia relevante para essa teoria e levando em conta o que foi proposto aqui, estaremos interessados em distinguir os recursos da língua que possibilitam a inovação por parte do falante. Alguns desses fenômenos foram mencionados quando comentamos a noção de subjetificação, na terceira seção, ou seja, trata-se dos fenômenos que introduzem a subjetividade dos falantes nas três perspectivas que citamos. É evidente que a reflexão sobre a subjetificação precisa avançar no sentido de pensar a articulação entre as três perspectivas que resumimos e sobre a relação entre essa noção e a de luta por reconhecimento. Esta última noção poderá também ser desenvolvida levandose em conta a noção de intersubjetificação, também proposta na literatura sobre gramaticalização (cf. TRAUGOTT; DASHER, 2005).

Enfim, como se pode perceber, este artigo é para ser tomado como um programa de trabalho que contém um bom número de questóes que requer desenvolvimento, mas creio que as propostas avançadas aqui merecem ser investigadas.

\section{Notas}

1 "No latim vulgar com frequência se confundem [w] e /b/ e com isso surge a confusão das formas de futuro (amabit) com as de perfeito do indicativo (amavit). Por outro lado, a passagem de $i$ a $e$ e a perda da quantidade vocálica levam a incômodas homofonias ou quasi-homofonias entre as formas do presente dos mesmos verbos (dices - dicis, dicet - dicit)" (itálicos do autor; tradução nossa).

${ }^{2}$ Cf. Meyer-Lubke (1914); Spitzer (1918); Vossler (1922); Meillet (1928); Bally (1935); Mattoso Câmara (1957); Gilli y Gaya (1973).

3 “(...) o futuro perifrástico se impôs devido à prevalência de uma atitude mental particular contrária à idéia meramente 'temporal' do futuro e favorável, em troca, a outros valores, modais e afetivos: o que seria determinante teria sido portanto uma necessidade expressiva para a qual o futuro sintético do latim clássico era inadequado, não tanto por suas deficiências formais, mas por seu próprio conteúdo semântico". (itálico do autor; tradução nossa). 
4 "Relevância do presente: uma noção aspectual que assinala o estabelecimento de uma conexão entre 'agora' e 'não agora'; um evento cronologicamente não presente (passado ou futuro) é visto como psicologicamente associado ao tempo presente". (itálicos da autora; tradução nossa).

${ }^{5} \mathrm{O}$ modal will, por exemplo, teve como fonte um verbo equivalente a want $\mathrm{e}$, como se sabe, o conteúdo da voliçãao permanece ainda nuançado em certos usos, como em Will you marry me?

6 "O Perfeito, que é composto por meio do presente de um auxiliar, é um tipo de tempo present tense e parece conectar o tempo presente com o passado... O Perfeito é um presente retrospectivo, que concebe o estado presente como um resultado do que aconteceu no passado". (itálico do autor; tradução nossa)

7 “(...) o resultado de uma ação anterior efetuada sobre um objeto dado". (tradução nossa)

${ }^{8}$ Já houve, no entanto, a formação de tempo composto com ter no pretérito perfeito, com valor de passado para indicar que em um momento do passado a ação estava consumada, como em: "E como teve feito nella o que quis, foi cercar D. João no forte em que esteve (COUTO - Dec 4, 10, 6, apud SAID ALI, 1971, p. 162)

${ }^{9}$ É notório o uso de palavrôes para expressar emoçôes.

${ }^{10}$ A preocupação com a objetividade científica era compreendida por Mead como uma postura behaviorista. No entanto, como proposto pelos tradutores franceses da obra de Mead, isto é, Cefái e Quéré (cf. MEAD, 2006, p. 44), trata-se, na realidade, da busca da comprovação empírica que surge num contexto de oposição à filosofia, sobretudo, em relação ao idealismo alemão que fez parte da formação de Mead.

${ }^{11}$ Cf. Lacan, 1966a; 1966b.

${ }^{12}$ Cf. Winnicott, 1975.

${ }^{13}$ Cf. Benjamin, 1988.

${ }^{14}$ Cf. Milroy, 1980; Bortoni-Ricardo, 2011.

${ }^{15}$ Essa proposta é também defendida por Cintra, 2008.

${ }^{16}$ Menon (Op. cit.) acrescenta que o emprego do gerúndio é, como se sabe, bastante produtivo em períodos pretéritos da língua e não é necessário apelar para a hipótese do empréstimo do inglês para explicar o atual gerundismo. 


\section{Referências Bibliográficas}

BALLY, C. Le Langage et la Vie. Zurich: Max Niehaus, 1935.

BENJAMIN, J. The Bonds of Love. New York: Pantheon Books, 1988.

BENVENISTE, E. Problemas de Linguistica Geral. São Paulo: Companhia Editora Nacional, 1976.

BORTONI-RICARDO, S. M. Do Campo para a Cidade. Estudo Sociolinguístico de Migração e Redes Sociais. São Paulo: Parábola, 2011.

BÜHLER, K. Sprachtheorie. Jena: Fisher, 1934.

BYBEE, J. Morphology: A Study of a Relation between Meaning and Form. Amsterdam: Benjamins, 1985.

CINTRA, M. R. (A Perífrase ir(pres.)+(es)ta ${ }^{\circledR}+$ gerúndio como Indício de Inovação Lingüística, Estudos Lingüísticos, v. 37, n. 1, p. 233-241, 2008.

COHEN, M. A. Gramaticalização e Reanálise na Língua Portuguesa: um estudo diacrônico, Caligrama, n. 1, p. 543-552, 1988.

CORÔA, M. L. M. S. O Tempo nos verbos do Português. Uma introdução à sua interpretação semântica, São Paulo: Parábola, 2005.

COSERIU, E. Sobre el Futuro Romance, Revista Brasileira de Filologia, n. 3, p. 1-9, 1957. DAMOURETTE, J.; PICHON, E. Des Mots à la Pensée, v: verbe. Paris: Biblioteque du Français Moderne, 1936.

FLEISCHMAN, S. The Future in Thought and Language. Diachronic evidence from Romance. Cambridge: Cambridge University Press, 1982.

FONSECA, A. M. H. A Perífrase Verbal ir+infinitivo e o Futuro do Dialeto Riopretano: um estudo na interface sociolinguística / gramaticalização. 2010. Dissertação (Mestrado) - Universidade Estadual Paulista de São José do Rio Preto, São José do Rio Preto, 2010.

GILLI, Y.; GAIA, S. Curso Superior de Sintaxis Española. Barcelona: Bibliograf, 1973. HEGEL, G. W. F. Système de la Vie Éthique. Paris: Payot, 1992 (=1893).

HEGENFELD, K. The Grammatica lization of Tense and Aspect. In: NARROG, H.; HEINE, B. (Ed.). The Oxford Handbook of Grammaticalization. Oxford: Oxford University Press, 2010. p. 577-591.

HILL, V. Vocatives and the Pragmatics-syntax Interface, Lingua, n. 117, p. 2077 2105, 2007. 
HOBBES, T. Leviatã. São Paulo: Abril Cultural, 1983(=1651). Os Pensadores.

HONNETH, A. Luta por Reconhecimento. A Gramática Moral dos Conflitos Sociais. São Paulo: Editora 34, 2003.

HOPPER, P.; TRAUGOTT, E. C. Grammaticalization. Cambridge: Cambridge University Press, 1993.

ILARI, R. Alguns Recursos Gramaticais para a Expressão do Tempo em Português: notas de um projeto de pesquisa. Estudos de Filologia e Lingüistica, n. 2, p.181-194, 1984.

JAKOBSON, R. Linguistics and Poetics. In: SEBEOK, T. A. (Ed.). Style in Language, Cambridge: MIT Press, 1960. p.350-77.

JESPERSEN, O. A Modern English Grammar on Historical Principles, Part IV: Syntax, Vol. III: Time and Tense. London: Allen \& Unwin, 1931.

JODOGNE, O. Il Veut Plevoit. Le Français Moderne, n. 23, p.280-286, 1955.

KURYLOWICZ, J. L'Évolution des Catégories Grammaticales. In: Problèmes $d u$ Langage, Paris: Gallimard, 1965. p. 55-71.

LACAN, J. Fonction et Champ de la Parole e du Langage en Psychanalyse. In: Écrits I. Paris: Seuil, 1966a.

LACAN, J. Du Traitement Possible de la Psychose. In: Écrits II. Paris: Seuil, 1966b. LANGACKER, R. W. Subjectification. Cognitive Linguistics, n. 1, p. 5-38, 1990. LANGACKER, R. W. Fondations of Cognitive Grammar. Volume 2: Descriptive Application. Stanford: Stanford University Press, 1991.

LANGACKER, R. W. Grammar and Conceptualization. Berlin: Mouton de Gruyter, 2000.

LANGACKER, R. W. Subjectification, Grammaticization and Conceptual Arquetypes. In: ATHANASIADOU, A.; CANAKIS, C.; CORNILLIE, B. (Ed.). Subjectification. Various paths to subjectivity. Berlin: Mouton de Gruyter, 2006.

LIGHTFOOT, D. Principles of Diachronic Syntax. Cambridge: Cambridge University Press, 1979.

LOBATO, L. C. R. Gênero Textual na Metodologia de pesquisa em Gramaticalização, 2010. 131f. Dissertação (Mestrado) - Universidade Federal de Minas Gerais, Belo Horizonte, 2009.

MAQUiaVel, N. O Principe. São Paulo: Abril Cultural, 1983(=1513). Os Pensadores. 
MATTOSO CÂMARA, J. Sôbre o Futuro Romance. Revista Brasileira de Filologia, n. 3, p. 221-225, 1957.

MEAD, G. H. L'Esprit, le Soi et la Société. Paris: PUF, 2006 (=1934).

MEILLET, A. L'évolution des Formes Grammaticales. In: MEILLET, A. Linguistique Historique et Linguistique Générale, Paris: Champion, 1958 (=1912).

MEILLET, A. Esquisse d'une Histoire de la langue Latine. Paris: Hachette, 1928.

MENON, O. Perífrases de Gerúndio: o que mudou?. In: CAGLIARI, L. C. (Org.).

O Tempo e a Linguagem. São Paulo: Cultura Acadêmica, 2008, p. 41-95.

MEYER-LÜBKE, W. Introduccion al Estudio de la Lingüistica Romance, Madrid:

Tip. de la Revista de Archivos, Bibliotecas y Museos, 1914(=1909).

MILROY, L. Language and Social Networks, Oxford: Blackwell, 1980.

MULLER, H. F. L'Époque Mérovingienne: synthèse de philologie et d'histoire. New York: Vanni, 1945.

NARROG, H. (Inter)subjectification in the Domain of Modality and MoodConcepts and Cross-linguistic Realities. In: DAVIDSE, K.; VANDELANOTTE, L.; CUYSCKENS, H. (Ed.). Subjectification, Intersubjectification and Grammaticalization, Berlin: Walter de Gruyter, 2010.

OCHS, E.; SCHIEFFELIN, B. Language has a Heart. In: OCHS, E. (Ed.). The Pragmatics of Affect, special issue of Text, n. 9, p. 7-25, 1989.

PLANTIN, C. Les Bonnes Raisons des Émotions. Berne: Peter Lang, 2011.

POSSENTI, S. Defendendo o gerúndio. Revista Discutindo Lingua Portuguesa, n. 1, v. 1, p.8-11, 2005.

RIBEIRO, I. A Formação dos tempos compostos: a evolução histórica das formas ter, haver e ser. In: ROBERTS, I; KATO, M. (Org.). Português Brasileiro. Uma viagem diacrônica, Campinas: Editora da Unicamp, 1993.

RICOEUR, P. Parcours de la Reconnaissance, Paris: Gallimard, 2004.

RIZZI, L. The Fine Structure of the Left Periphery. In: HAEGEMAN, L. (Ed.). Elements of Grammar: Handbook of Generative Syntax. Dordrech: Kluwer, 1997. p. 281-344.

RUBIN, A. Studies in Semitic Grammaticalization. 2004. Tese (Doutorado) - Harvard University, Harvard, 2004.

SAID ALI, M. Gramática Histórica da Língua Portuguesa. São Paulo: Melhoramentos, 1971.

SAPIR, E. Linguistique. Paris: Gallimard, 1968. 
SILVA, A. da A Expressão da Futuridade no Português Falado. Araraquara: Laboratório Editorial / UNESP, 2002.

SPEAS, M. Evidenciality, Logophoricity and the Syntactic Representation of Pragmatic Features. Lingua, n. 114, p.255-276, 2004.

SPITZER, L. Über das Futurum cantare habeo. In: Aufsätze zur romanischen Syntax und Stilistik. Halle: Niemeyer, 1918. p.173-80.

TRAUGOTT, E. Subjectification in Grammaticalisation. In: STEIN, D.; WRIGHT, S. (Ed.). Subjecivity and Subjectivisation. Cambridge: Cambridge University Press, 1995. p. 31-54.

TRAUGOTT, E.; DASHER, R. B. Regularity in Semantic Change. Cambridge: Cambridge University Press, 2005.

VIANNA, H. L. G. A Estrutura Modal+Infinitivo em português: Gramaticalização e Modalização. 2000. Dissertação (Mestrado) - Universidade Federal de Minas Gerais, Belo Horizonte, 2000.

VITRAL, L. O Papel da Freqüência na Identificação de Processos de Gramaticalização, Scripta, v. 9, n. 18, p.149-177, 2006.

VOSSLER, K. Neue Denkformen im Vulgärlatein. In: Hauptfragen der Romanistik. Festschrift für Philipp August Becker. Heidelberg: Winter, p.170-191, 1922.

ZAGORIN, P. Hobbes and the law of nature. Princeton: Princeton University Press, 2009. 